\title{
Maintaining Harmonious Social Environment among Fishermen on the North Coast of Central Java through Seafaring Myths
}

\author{
Agus Subiyanto ${ }^{1 *}$, Nurhayati ${ }^{1}$, and Astri Adriani Allien ${ }^{1}$ \\ ${ }^{1}$ Department of Linguistics, Faculty of Humanities, Diponegoro University, Semarang - Indonesia
}

\begin{abstract}
Traditional fishermen in the North Coast of Central Java commonly have a simple life economically, and their income is sometimes sufficient only for fulfilling their very basic needs, especially food. However, their social life and environment are worth appreciating. The tough life in the sea has taught them how to behave with others. They believe that the sea is inhabited by many supernatural creatures, and so they have to avoid doing improper behavior as reflected in seafaring myths. This paper aims to discuss the kinds of seafaring myths related to forbidden acts among fishermen in the North Coast of Central Java, and the factors causing their belief of the myths. In this case, an eco-linguistics perspective is used to uncover the phenomena of the seafaring myths. This study used the data taken from interviewing fishermen, randomly chosen as the informants, who live in fishing areas in Semarang, Kendal, and Demak. The result of the study shows that seafaring myths still exist, and they are preserved because of the empirical facts they often experience when violating the myths. From an eco-linguistic perspective, the existence of the myths cannot be separated from biological, sociological, and ideological aspects of the fishermen.
\end{abstract}

Keywords: seafaring myths; fishermen; Central Java; eco-linguistics.

\section{Introduction}

Traditional fishermen in the North Coast of Central Java are tough people. They go catching fish in the sea using a fishing net dragged by a canoe without being accompanied by any assistant. This is done because they usually do not get enough fish to share with another fisherman. The uncertain condition of catching fish has encouraged the fishermen to work independently, and so they commonly have their own canoe for their fishing activities. This is the portrait of traditional fishermen in the fishing areas under investigation.

For fishermen, the sea is a part of their life, and so they have to show respect to the sea in order that they can do their fishing activities safely. In this context, there are some 'rules' about the sea or seafaring myths that they have to follow before and during their fishing activities. These seafaring myths have been believed by many fishermen to have an effect on their safety, and even some accidents in the sea are often related to a violation of these rules.

The habit of keeping good behavior when doing fishing activities has also an impact on fishermen's social interactions, resulting in their harmonious social environment. This study aims to discuss the kinds of seafaring myths related to forbidden acts among fishermen in the North Coast of Central Java, and the factors causing them to believe in the myths. In this case, the theory of eco-linguistics is used to explain the phenomena above.

\section{Literature Review}

Studies on fishermen on the North Coast of Central Java focusing on their social life, cultural values, and folklore have been conducted by some researchers. For example, Fama [1] studied the social life of the coastal communities, especially in Tambak Lorok fishing area of Semarang, Central Java, and the problems they faced, as well as the role of the fish auction place for them. The results showed that the coastal communities in the area commonly work as fishermen, fish sellers, shrimp paste makers, and smoked fish sellers. In terms of the character, they commonly have a strong principle, and so they may find it difficult to accept a change. The study also found that the relationship between the people in the fishing community was quite close, and they prioritized togetherness rather than individual interests. This is interesting to note considering that in the modern era, togetherness values have generally faded in various aspects of people's lives. However, it does not happen to the fishing communities in Tambak Lorok.

A recent study on the cultural values of fishermen in Central Java was conducted by Nirmala [2], who discussed the sociocultural expressions as a representation of the identity of fishing communities on the north coast of Central Java. The study took samples from fishing communities in four areas, which are Kendal, Semarang, Demak, and Jepara. The findings of the study show that the fishermen use specific sociocultural expressions related to fishing activities, social structures, tools, and ships to catch fish. These

* Corresponding author: agussubiyanto@live.undip.ac.id 
expressions are unique and they are only used among the fishermen. In this case, the use of the expressions reflects the identity of fishermen.

Studies on folklores and their role in society have also been conducted. For example, Nurhayati [3] examined deer tales from the perspective of critical discourse analysis. In her research, Nurhayati found that the deer tales, as a part of the Javanese folklores, contained stories that depicted social wrongs, constructed through understanding the meaning of 'clever' negatively. This understanding is carried out from generation to generation, which is reflected in the storytelling model, from which the readers, in this case, the children are assumed to have shared knowledge about the nature of the deer and understand it in a natural way.

Another study that examined folklore was conducted by Sutaryanto [4], who discussed the role of folklore in developing the Indonesian multicultural knowledge among elementary school students. The article found that folklore can be used as a medium of education and educational resources or learning materials for school children, especially at the elementary school level. This finding is similar to that of the study by Adi [5], who discussed the role of folklore in developing the character building. In addition, the most recent study on myths in relation to education was conducted by Rao [6] who studied myths in the history of Indian education.

The previous studies above indicate that folklores play an important role in education because they can shape the character of the society. However, so far there have not been any studies on how seafaring myths as a part of folklore have an impact on creating harmonious social relationships among fishermen. In addition, the studies on folklores are commonly conducted using a language teaching approach or a discourse analysis perspective. In this study, however, we use an eco-linguistic perspective to uncover the phenomena of folklores, especially seafaring myths.

According to the eco-linguistic point of view, as seen in Steffensen [7], language forms social praxis, and at the same time, language is shaped by social praxis. Language is a social product of human activities and at the same time language also changes and influences human activities or social praxis. Thus, there is a dialectical relationship between language and social praxis. The concept of social praxis in this context refers to all actions, activities, and behaviors of the people, both to fellow citizens and to the natural environment around them. In dialectical theory, social praxis includes three dimensions, namely ideological, sociological, and biological dimensions. The ideological dimension is an individual and collective psychological, cognitive and mental system. The sociological dimension relates to how we regulate relationships with others, for example in families, between friends, neighbors, or in a larger social environment, such as the political system in a country. Biological dimensions are related to our existence in relation to other species such as plants, animals, earth, sea, and others [8].

The implication of the dialectical relationship between language and social praxis is that the study of language also means a study of social praxis, and thus language theory is also a social praxis theory. For this reason, ecolinguistic studies in dialectical theory are studies of the interrelation of ideological dimensions, sociological dimensions and biological dimensions in language [9]. In this study, the eco-linguistic perspective is used to explain the phenomena of seafaring myths believed by the fishing communities in the North Coast of Central Java. In this case, like language, seafaring myths are a part of the culture of the users, and so the study of seafaring myths cannot be separated from the study of social praxis.

\section{Research Method}

This study used an interview method to collect the data on seafaring myths. In this case, six fishermen from three fishing areas in Semarang, Demak, and Kendal respectively were chosen as the samples of this study. In this case, we used a purposive random sampling method. The criteria for choosing the samples are as follows. First, they were born in a fishing area in Semarang, Demak, or Kendal. Second, they live in the area as fishermen. Third, they are not much influenced by other cultures as seen from their marriage of the same culture, and their length of stay in the area

The data of the study were analyzed using the distributional method to classify the kinds of seafaring myths and the factors influencing their belief in the myths from an eco-linguistic perspective.

\section{Result and Discussion}

\subsection{Kinds of Seafaring Myths}

Traditional fishermen commonly go canoeing to catch fish early in the morning and come back home in the afternoon. Before and during their fishing activities, there are some myths that they believe. The following are some seafaring myths used by fishermen in the North Coast of Central Java that play an important role in shaping their character.

\subsubsection{Never go to the sea on the day your parents died}

Fishermen usually use the Javanese calendar for cultural, metaphysical, and spiritual purposes. Based on the calendar, they believe that the day their father and mother died is very sacred. On that day, fishermen should pray and show respect to their parents, and should not go to the sea. They believe that if they go to the sea on that day, many obstacles will happen to them. This myth is strongly believed by fishermen because they often experience bad lucks on the sea due to the violation of the myth. Some incidents, such as the sudden change of weather and the occurrence of strong wind are often claimed irrational to them, and these can endanger their safety. In addition, some of them claimed that it is hard to find fish on the day their parents died. 


\subsubsection{Never mention land animals on the sea}

Javanese people often swear by using animal names, such as asu 'dog', babi 'pig', and sapi 'cow'. When working on the sea, fishermen are not allowed to swear or even mention animal names. They believe that mentioning land animals will result in bad lucks on the sea, such as the coming of high wave that can endanger their safety. In this case, if they have to say something about land animals, they have to say something else to substitute the animal names. The name ayam, 'chicken' for example, should be substituted with the word iber, and sapi 'cow' should be substituted with saplin.

\subsubsection{Never talk about ghosts on the sea}

The sea is more sacred than the land, said some fishermen. They believe that there are many ghosts and the like in the sea, and if you disturb them, bad luck such as a boat accident may happen to you. Some of them claimed that they sometimes see ghostlike creatures next to them. Some other fishermen also said that they sometimes see something like a piece of land with coconut trees moving on the see. Based on these experiences, they believe that the sea is inhabited by many ghosts, devils or the like. To be safe during their fishing activities on the sea, the fishermen should not disturb them, and this can be done by avoiding talking about them. In addition, they are also supposed not to spit anywhere on the sea because the place where you spit may be the place where ghosts live. In short, respecting others including ghosts is very important for fishermen in order that they can work on the sea safely.

\subsubsection{Never feel pessimistic on the sea}

Words are prayers. This expression may describe fishermen's belief in staying optimistic in life. This attitude should be maintained during their fishing activities on the sea. They believe that when you feel or say something pessimistic, you will get what you say. There are a lot of incidents that they experienced as a consequence of what they said. For example, once there was a fisherman getting a lot of fish on his boat, and he said that the boat would not strong enough to carry the fish and it could sink because of this. Not long after that, the boat sank and the fish was gone in the sea. Another story was experienced by a fisherman being upset because he had not got any fish. He said that he had not got even a half fish. Shortly after that, he got a dead fish with a half part missing. These experiences have made the fishermen believe that they should not say something negative or pessimistic.

\subsection{The Role of Seafaring Myths in Creating Harmonious Social Relation among Fishermen}

The way fishermen behave when working on the sea to catch fish has a very positive impact on how they interact with other people in their community. For fishermen, togetherness and harmony are important in their lives. They tend to prioritize togetherness rather than individual interests [1], and so social conflicts almost never occur within their community. In the ecolinguistic perspective, the harmonious social relation cannot be separated from the biological environment of the fishermen, which then shapes their ideology. In the following, we will explain how the biological, social, ideological aspects of the fishermen which all together shape their character as tough people with high solidarity and togetherness.

\subsubsection{The biological Aspect}

The biological aspect or dimension relates to the natural environment where the fishermen live. In this case, the sea is the central part of the biological environment. For the fishermen, the sea is a part of their life because most of them do not have an alternative of working other than as fishermen. As a place where they work, the sea can provide a living, especially when they get a lot of fish from their fishing activities. However, it can also cause a disaster or even death. The fishermen believe that they have to show respect to the sea in order that they can get a lot of fish and back home safely. This phenomenon has triggered the fishermen to behave properly when doing their activities on the sea. This is done by avoiding forbidden acts as outlined in the seafaring myths above. By doing this, the fishermen believe that they can create harmonious relationship with the sea.

\subsubsection{Sociological Aspect}

The fishermen's habit of behaving well on the sea has given an impact on their harmonious social interaction. They keep the principle of togetherness among their community by showing mutual respect. This is done, for example by avoiding the acts that can harm other people's feelings. One of the examples can be seen from their habit of not showing off when they get a lot of fish or what they call nyarak 'getting a lot of fish'. On the other hand, they cannot complain or even blame other people when they do not get fish or what they call blong. It is a forbidden act for the fishermen to be arrogant in any condition. In addition, the fishermen also have to keep their 'polite' behavior by not swearing or gossiping about others. This behavior cannot be separated from what they usually do when working on the sea. In this case, the sea as the fishermen's biological environment is similar to their social environment in which there are many 'inhabitants'.

\subsubsection{Ideological Aspect}

The ideological aspect relates to how the fishermen perceive the world. The existence of seafaring myths cannot be separated from the fishermen's belief in supernatural beings or creatures. Empirical experiences that they got or heard from their friends of the same community have taught them how to deal with supernatural beings. Some of them even believe that the sea has power, and so they should ask for permission 
before going catching fish in the sea. However, some other fishermen also believe that it is God has power, and so they only believe in and pray to God for their safety. Apart from this, their belief in supernatural beings has led them to behave well whenever they are, and this has made seafaring myths still exist among the fishermen.

The facts about the seafaring myths mentioned above have an impact on the fishermen society in facing the challenge of the 4th industrial revolution era, where efficiency in all sectors is extremely demanded. Their belief in seafaring myths can influence the productivity level of their fishing activities. Their habit of not going fishing on certain days because of seafaring mythsrelated reasons can reduce their fishing catch. From an economic point of view, this habit is not productive because they cannot go fishing anytime. This is also one of the reasons why the economic condition of traditional fishermen is generally less encouraging, and in fact, most fishermen in this area are economically poor [10]. However, their belief in seafaring myths has a positive impact, especially to preserve local wisdom, which will, in turn, preserve their culture as a traditional fishing community.

\section{Conclusion}

Seafaring myths among the fishermen in the North Coast of Central Java are still believed and preserved. Various incidents happening to fishermen in the sea are often related to the violation of the myths. The habit of behaving well during their fishing activities has a positive impact on the social interaction of the fishermen. The principle of togetherness among the fishermen has made them have a harmonious social environment. From the eco-linguistic perspective, this phenomenon cannot be separated from the biological, sociological, and ideological aspects of the fishermen.

\section{References}

1. A. Fama, J. Sbd 11, 2 (2016)

2. D. Nirmala, The 7 th Indonesia Japan Joint Scientific Symposium (IJJSS) (2016)

3. Nurhayati, Prosiding Seminar Tahunan Linguistik (2016)

4. Sutaryanto, A. Kartikasi, Proceedings International Seminar Faculty of Education-FoE (2016)

5. W.T. Adi, A.H. Mustaqim, Proceeding of the $62^{\text {nd }}$ TEFLIN International Conference (2015)

6. P.V. Rao, Esp.T. y E 6, 2 (2019)

7. S.V. Steffensen, Language, Ecology and Society - a Dialectal Approach, Continuum, London (2007)

8. J. Bundsgaards, S.V. Steffensen, Dialectical Ecolinguistics, the University of Odense (2000)

9. J.C. Bang, J. Door, Eco-Linguistics: A Framework (1993)

10. Mussadun, P. Nurpratiwi, J. P.W.K 27, 1 (2016) 